\title{
Về mối liên thông giữa thị trường bất động sản, vốn và tiền tệ
}

\author{
Vương Quân Hoàng \\ Nguyễn Hồng Sơn \\ Tạp chí Cộng sản \\ Vol. 79 , No. 4, Serial 786, pp. 56-65 \\ (ISSN: 0866-7276)
}

Ngày 15 tháng 4 năm 2008

Hà Nội, Việt Nam 


\section{VỀ MỐI LIÊN THÔNG GIỨA TH!̣ TRỪ̛NG BÁ́T DộNG SẢN, VỐN VÀ TIỀN Tị̂}

VUƠNG QUÂN HOÀNG * - NGUYỄN HỒNG SƠN **

Trong giai đoạn 2005 - 2007, nền kinh tế Việt Nam đã có sư buit phá về tăng trường, cùng với sự tinh vi và phức tạp gia tăng đáng kể bời các thị trường vốn hoạt động mạnh mê, các sản phẩm tài chính đa dạng hơn và nhu cầu đầu tư tăng mạnh. Quá trình liên thông giữa các thị trường bất động șain, vốn và tiền tẹ đang được nhắc tới nhiều, nhưng đó mới chi là sự hiểu biết trực giác. Công tác quy hoạch chính sách tài chính, tiền tệ cần nhũng nghiên cứu đủ sâu để có thể nhận biết các đặc tính, thậm chí dự báo các trạng thái kinh tế với các xác suất đủi tin cậy.

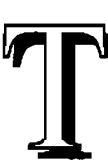

Ừ khi Việt Nam tiến hành đổi mới toàn diện nền kinh tế (năm 1986), tầm quan trọng của thị trường bất động sản và tài chính từng bước được khẳng định. Năm 2000 , một thể thức mới ở mức tinh vi cao độ của thị trường vốn Việt Nam ra đồi: thị trường chứng khoán (TTCK), nơ các tài sản tài chính là cổ phần doanh nghiệp được trao đổi. Sự ra đời của thị trường chứng khoán Việt Nam (TTCKVN) đánh dấu bước tiến tới sự đầy đủ của dạng thức kinh doanh tài chính tại Việt Nam.

Năm 2007, nền kinh tế Việt Nam được chúmg kiến một lần nữa giá bất động sản tăng lên nhanh chóng. Theo dòng thông tin đầu năm về hoạt động kinh doanh chứng khoán có lãi của nhiều nhà đầu tu vào cuối năm tài chính 2006, một phần lãi đáng kể được những nhà buôn chứng khoán Việt Nam và không loại trừ cả những ngườ nước ngoài nhậy bén chuyển thành tiền mặt, rồi đầu tur vào bất động sản đô thị. Sau đó, khi TTCKVN không thể quay trở lại mức đỉnh cao 1.173 của ngày 18-3-2007, và liên tục trồi sụt, xu hướng đầu tư bất động sản trở nên rõ nét, với mức giá ngày càng cao hơn, theo các khảo sát liên tục của giới truyền thông. Hoạt động kinh doanh bất động sản rất nhộn nhịp, không chỉ trong giới đầu tư - đầu cơ - kinh doanh bất động sản, mà cả các cơ quan cung cấp tài chính như quỹ đầu tư, ngân hàng thương mại và các doanh nghiệp có thặng dư vốn cổ phần.

Tìm hiểu kỹ hơn về sự liên thông giữa các thị trường rất quan trọng ở Việt Nam là bất động sản, vốn và tiền tệ là một việc hết sức cần

* TS, Đại học Tổng hợp Bruxelles (Bỉ)

** Th.S, Phó Vụ trường, Vụ Kinh tế, Văn phòng Trung ương Đảng 
thiết, sẽ tạo ra những nhận thức có ích cho công việc lập chính sách kinh tế vĩ mô (nguồn lực nào, ảnh hương ra sao tới việc làm, tăng trưởng, lạm phát...) và vi mô (cơ chế nào thúc đẩy giao dịch, hạn chế rủi ro, và tạo sự công bằng...).

\section{1 - Sự liên thông bất động sản, vốn và tiền tệ}

Năm 2007 được đánh giá là một năm sôi động với nền kinh tế Việt Nam. Các thị trường trọng yếu, tập trung nhiều nguồn lực và thu hút sự chú ý của công chúng: bất động sản, vốn và tiền tệ không phải ngoại lệ. Nhiều dấu hiệu thể hiện quan hệ liên thông tương tác mạnh giữa các thị trường này được ghi nhận từ thực tế vận động và các sự kiện kinh tế.

\section{a - Tương tác giữa thị trường bất động} sản và chứng khoán

Bất động sản gần như mối quan tâm thường trực của cá nhân mỗi khi tiềm lực tài chính được cải thiện hoặc vào lúc cần sắp xếp lại cơ cấu tài sản nắm giữ. Đặc tính này càng thể hiện rõ hơn khi nền kinh tế Việt Nam có những bước tiến tích cực, của cải tích lũy của người dân nhiều hơn. Trong thập kỷ 90 của thế kỷ trước, có thể ghi nhận việc xã hội xem bất động sản như một phương tiện lưu trũ giá trị ưa thích bên cạnh vàng và ngoại tệ mạnh (phổ biến là đô-la Mỹ). Xu hướng tăng giá bất động sản cũng là động lực quan trọng khiến thị trường này ngày một sôi động và lấn át các hình thức đầu tư và tiết kiệm truyền thống.

Ra đời từ giữa năm 2000 , thị trường chứng khoán mang lại một phương thức mới để sử dụng nguồn vốn thặng dư trong xã hội, không chỉ lưu trữ giá trị mà còn có khả năng mang lại nguồn lợi đáng kể trong thời gian ngắn. Trong khoảng 6 năm hoạt động đầu tiên, thị trường này chưa nhận được nhiều sự quan tâm của các tác nhân trong nền kinh tế. Tuy nhiên, với sự thăng hoa của thị trường chứmg khoán từ nửa cuối năm 2006 và trong năm 2007, đầu tư trên thị trường chứng khoán thực sự trở thành lựa chọn luôn được đưa ra cân nhắc cùng với bất động sản. Thậm chí, tại nhiều thời điểm cao trào, tập trung tài lực cho kinh doanh chúmg khoán còn là lý do để rời bỏ tài sản nhà đất đang nắm giữ (đặc biệt với các quyết định cá nhân).

Quý I năm 2007 ghi nhận mức cầu bất động sản tăng vọt của những nhà đầu tư thắng lợi trên mặt trận chứng khoán. Lượng tiền mặt thu được từ các khoản lợi nhuận đầu tư chứng khoán không chỉ góp phần gia tăng số lượng giao dịch bất động sản mà còn tạo tính thanh khoản rất cao cho thị trường này. Chính điều này, có lẽ, là lý do trực tiếp nhất dẫn tới "cơn sốt" bất động sản trong quãng thời gian còn lại của năm 2007.

Giá nhà đất trong quý II năm 2007 tăng chóng mặt. Tác động tâm lý thể hiện khá rõ trong hành vi vội vã tham gia thị trường bất động sản. Những người thực sự có nhu cầu sử dụng cố gắng tìm và sở hữu món bất động sản phù hợp với nguyện vọng và khả năng tài chính trước khi giá leo thang. Một nhóm khác, chiếm từ $50 \%$ - $60 \%$ người mua vào bất động sản, nhanh chân thực hiện các giao dịch để đầu cơ, chờ giá lên.

Sụt giảm của thị trường chứng khoán từ sau tháng 4-2007 phần nào buộc công chúng điều chỉnh mức kỳ vọng lợi nhuận đầu tư và xem xét lại tiềm lực tài chính, cân nhắc một trong hai lựa chọn: bất động sản hay chứng khoán. Sang đầu quý III năm 2007, giá nhà đất bình ổn hơn. Và, trước những biến động khó lường của tài sản tài chính, nguồn lực đầu tư một lần nữa được quả quyết tập trung vào bất động sản với những tài sản thực. Giá bất động sản không tăng đột ngột nhưng liên tực đi lên, tập trung vào căn hộ chung cư cao cấp.

Cuối năm 2007 đầu 2008, những kết quả thất vọng trên thị trường chứng khoán càng 
như cổ vũ nhiều tay chơi chứng khoán tìm đến bất động sản. Giá nhà đất bước vào vòng xoáy tăng cao mới.

Bảng 1: Tưong quan giữa thị trường bất động sản và chỉ số thị trường chúng khoán

\begin{tabular}{|l|l|l|}
\hline & Giá bất động sản & Vn-Index \\
\hline Quý I/2007 & Tăng & Tăng \\
\hline Quý IV/2007 & Tăng mạnh & Giảm \\
\hline Quý III/2007 & Ốn định & Giảm \\
\hline Quí IV/2007 & Tăng mạnh & Giảm mạnh \\
\hline
\end{tabular}

Quan hệ tương quan giữa bất động sản và chứng khoán rất rõ ràng. Các tác động có khi cùng chiều, lúc lại ngược chiều do chịu nhiều ảnh hưởng của yếu tố tâm lý. Khi thị trường chứng khoán rơi vào trạng thái giảm sâu như thời gian qua, cả lượng giao dịch và mức giá trên thị trường bất động sản đều suy giảm mạnh. Hiện tượng này phần nào phản ánh tính bầy đàn của giới đầu tư Việt Nam, đặc biệt trong tình huống bất lợi của thị trường, đã được chứng minh bằng dữ liệu thống kê của TTCK Việt Nam.

b - Tính đa dạng của các sản phẩm tín dụng và tỷ trọng tăng lên của dư nợ bất động sản tại ngân hàng thương mại

Các giao dịch bất động sản có quy mô chiếm tỷ trọng lớn tương đối so với nguồn thu nhập và năng lực đầu tư. Các ngân hàng thương mại rõ ràng không thể bỏ qua thị trường quá tiềm năng này. Ngay trong năm 2007, nhiều chương trình tín dụng bất động sản hấp dẫn được giới thiệu tại Eximbank, ABBank, Techcombank, Habubank...

Các chương trình tín dụng bất động sản nhà ở này có chung một số đặc điểm đáng chú ý: Bất động sản hình thành từ nguồn tín dụng đi vay được sử dụng làm tài sản thế chấp; thời hạn cho vay 10 hay 15 năm, cá biệt có khoản vay tới 30 năm; lãi suất được điều chỉnh theo từng kỳ ngắn hạn, thường là 3 tháng; mức lãi suất được áp dụng thống nhất cho các khách hàng theo quy định của mỗi ngân hàng. Phân loại tín dụng chỉ duy nhất phục vụ quyết định cấp hoặc không cấp tín dụng.

Quy trình thực hiện tín dụng bất động sản tại hệ thống ngân hàng thương mại hiện tại bảo đảm an toàn. Khả năng vỡ nợ hầu nhu không thể xảy ra. Trên thực tế, hạn mức tín dụng được các ngân hàng cung cấp thường không quá $50 \%$ của $70 \%$ giá trị thị trường bất động sản thế chấp. Nghĩa là tỷ lệ tài trợ của ngân hàng với một khoản đầu tư bất động sản của cá nhân thông thường dừng ở mức $35 \%$ giá trị tài sản. Điều này là động lực thúc đẩy người sử dụng tín dụng thanh toán đầy đủ phần lãi thường xuyên do thiệt hại của họ có thể lên tới $65 \%$ giá trị tài sản. Trường hợp hi hữu phải phát mãi tài sản thì tính thanh khoản cũng được bảo đảm chắc chắn nhờ mức định giá tài sản thế chấp thấp.

Với các dự án phát triển bất động sản kinh doanh, phần thẩm định của ngân hàng sẽ rất chặt chẽ và tập trung vào tính khả thi, mức độ sinh lời của dự án, tiềm lực tài chính, kế hoạch bán hàng... của đơn vị chủ dự án.

Mặc dù chính sách tín dụng được áp dụng khá chặt chẽ, tỷ trọng dư nợ tín dụng trên tổng số dư nợ của hệ thống ngân hàng thương mại đã tăng lên đáng kể trong thời gian qua. Khảo sát nhanh của website www.asset.vn cho thấy, tính tới đầu tháng 3-2008, tỷ lệ này trong hệ thống ngân hàng thương 'mại Việt Nam dao động ở mức từ $20 \%-40 \%$. Ngân hàng nhà nước khuyến cáo sẽ có kế hoạch tiến hành thanh tra những ngân hàng thương mại có tỷ lệ cấp tín dụng bất động sản cao vượt mức $30 \%$ tổng dư nợ.

Trong lịch sử, bất động sản đã từng là nguyên nhân duy nhất gây ra sự phá sản 4.800 ngân hàng của Hoa Kỳ trong những năm 1931 - 1933. Với các cấu trúc chi tiêu, hàng trăm thành phố và chính quyền địa phương đã bị vỡ nợ, mất khả năng chi trả vào năm 1933 
cũng chỉ vì dự báo khả năng nguồn thu dựa chủ yếu vào hoạt động kinh doanh bất động sản, và giả định căn cứ vào lúc tăng trướng trông có vẻ khả quian nhất.

Thời kỳ này, các ngân hàng khi gặp vấn đề phá sản với hàng đống tài sản đóng băng do đầu tư quá nhiều vào bất động sản cũng thường đổ lỗi cho tình trạng: "đầu cơ quá mức."

Đối với các tổ chức kinh doanh bất động sản, khoản thu trước từ khách hàng rất hấp dẫn. Bởi vậy, họ đưa ra nhiều công cụ tài chính và cách thức sáng tạo để tối đa dòng vốn này. Quy mô đáng chú ý của các khoản ứng trước từ khách hàng còn được thể hiện qua quy định của Chính phủ không cho phép bán "sớm" bất động sản trên giấy. Nhưng như vậy, không có nghĩa các doanh nghiệp từ bỏ nguồn thu này. Khoản tiền úng trước có những tên gọi mới "tiền đặt mua," "tiền thành ý..." Trong tháng 2-2008, một sản phẩm tài chính mới được giới thiệu: trái phiếu doanh nghiệp kèm theo quyền mua căn hộ chung cư trong dự án sắp khởi công.

Dấu hiệu của sự liên thông giữa các thị trường bất động sản - vốn - tiền tệ còn có thể được ghi nhận thông qua sự tham gia của đông đảo các công ty có dư tiền vốn hoặc năng lực tín dụng (có phần đóng góp quaan trọng của các khoản thặng dư vốn cổ phần) vào līnh vực bất động sản mặc dù đó không phải là ngành nghề kinh doanh chính. Tiềm năng tăng trưởng của thị trường này cũng là yếu tố hấp dẫn nhiều nhà đầu tư tài chính với cổ phiếu của nhóm doanh nghiệp bất động sản.

\section{c - Quá trình tái tạo bất động sản}

Liên thông giữa thị trường bất động sản và tài chính còn có thể quan sát được rõ nét qua quá trình tái tạo bất động sản. Hai ví dụ dưới đây minh họa cho các tình huống dễ bắt gặp trong điều kiện thực tế.
Bất động sản sinh ra bất động sản. Giả sử ta có bất động sản $\mathrm{A}$, với giá trị 10 tỉ đồng, được cho thuê với giá 100 triệu đồng/tháng cho chủ kinh doanh nào đó; hợp đồng thuê cho phép lấy trước tiền của 3 năm, ấn định giá tới 5 năm. Nguồn thu ngay lập tức là: $36^{*} 100$, và một khoản chiết khấu a\% của $24 * 100$. Phần hoa lợi gia tăng này có thể được sử dụng để tái đầu tư bất động sản mới. Và quá trình này tiếp diễn...

Các công ty kinh doanh có bất động sản kinh doanh, tạo ra lãi. Việc niêm yết cổ phiếu trên TTCK giúp giá có thể tăng so với mệnh giá $500 \%(\mathrm{P} / \mathrm{B}=5)$. Bất động sản được đánh giá cao lên 5 lần. Năng lực vay vốn của doanh nghiệp tăng lên với ngân hàng, có thể giúp họ vay một mức $\mathrm{X}$. Mức này có thể giúp họ tiếp tục tái tạo bất động sản. Nếu họ lại sử dụng vốn vay này để tạo dựng một công ty kinh doanh bất động sản mới, với suất vay nào đó, thì một chu trình mới tạo ra 5 lần giá trị lại được bắt đầu. Quá trình tạo ra tiền vô tận này sẽ không dừng lại về mặt lý thuyết, và trong thực tế cũng đã có giai đoạn xảy ra gần như vậy. Nó chỉ dừng lại khi bị giới hạn tín dụng, và nguồn đầu tư bổ sung. Với cổ phiếu ITA (Công ty cổ phần Khu công nghiệp Tân Tạo), mức giá thấp nhất cũng trên 5 lần. Thời điểm tăng cao có thể tới 17 lần. Và giá có xu hướng ổn định quanh mức 10 lần.

Biểu đồ: Biến động giá cổ phiếu ITA Công ty cổ phần Khu công nghiệp Tân Tạo

$\rightarrow \pi \mathrm{A}$

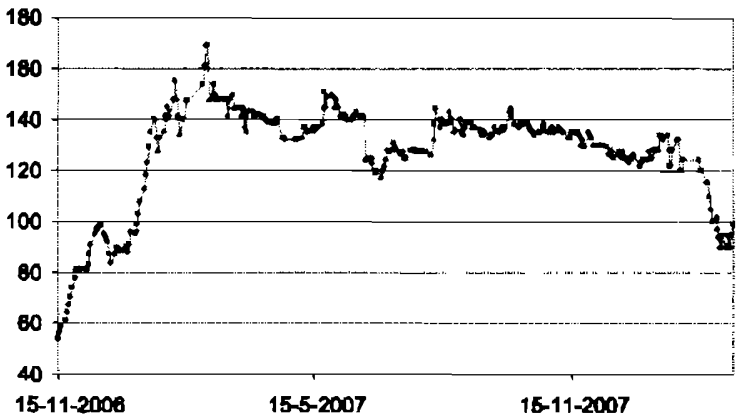

Nguồn: www.asset.vn 
Đây là dạng khác của rent-seeking - khái niệm kinh tế học do Anne Krugger (từng giữ vị trí Phó giám đốc Quỹ Tiền tệ quốc tế IMF) đưa ra. Bà Krugger cho rằng, khi được ưu đãi và bảo vệ, các doanh nghiệp trong nước sẽ không chịu cải cách để nâng cao tính cạnh tranh mà chỉ tìm cách xoay xở để giữ lại bổng lộc từ những ưu đãi và trợ giúp của nhà nước.

\section{2 - Những vấn đề trọng yếu và gọi} mở hướng nghiên cứu chính sách

a - Chứng khoán hóa có giúp giải quyết rủi ro vay nợ bất động sản?

Các chính phủ trên thế giới thường áp dụng ba giải pháp cơ bản để xử lý xung đột trong hoạt động cho vay của ngân hàng, là: ban hành các quy định về nghiệp vụ, đại chúng sở hữu ngân hàng, và chứng khoán hóa tài sản cầm cố.

Một giải pháp thứ tư, theo cách tiếp cận không có sự can thiệp của chính phủ, trong định giá nợ và chuyển giao rủi ro là bán bảo hiểm với tình huống vỡ nợ tín dụng. Thị trường bảo hiểm vỡ nợ tín dụng đã được hình thành tại Hoa Kỳ. Cuối năm 2006, thị trường này tăng trướng đến mức kinh ngạc với giá trị đạt 20.000 tỉ đô-la Mỹ. Hoàn toàn tương phản, giá trị của thị trường các nghĩa vụ nợ có bảo đảm $(\mathrm{CDO})$, cùng thời điểm đó, ước tính vào khoảng 2.000 tỷ đô-la. Khoảng cách là rất lớn và sản phẩm hoán đổi thống lĩnh thị trường. Bởi vậy, có thể cho rằng, các sản phẩm phái sinh rất hữu ích trong việc cung cấp thông tin hỗ trợ giải quyết vấn đề định giá rủi ro.

\section{b - Vấn đề đặt cọc}

Việc bất động sản được xem như tài sản lớn, khiến người ta có quy chế đặt cọc trong quá trình giao dịch. Khảo sát tiền cọc là bài toán có ý nghĩa lớn, vì nó chiếm dụng vốn của nhau.

Để tạo sự công bằng giao dịch, mức đặt cọc này rất có ý nghĩa. Nếu được định giá đưng, nó là một dạng "quyền chọn thực"- một công cụ tài chính rất đắc lực ra đời khoảng những năm 80 của thế kỷ trước. Quyền chọn thực được thiết kế như một hợp đồng bảo hiểm cho người nắm "quyền được mua" về sau này, trong một thời hạn nhất định. Với nghĩa này, người nhận tiền cọc có nghĩa vụ phải thực hiện việc bán với mức giá xác định và tại khoảng thời gian xác định (giao nhà).

Do chưa trở thành kỹ thuật có tính úng dụng rộng rãi, không ai đánh giá giá tri này. Một mặt khác, do hệ thống thống kê và công cụ tài chính thực hành không tốt, việc tiến hành các tham số cho đánh giá này cũng không thấy thực hiện. Do vậy, có thể ngờ rằng, người ta có xu hướng ra giá cọc cao hơn, hay nói cách khác, quyền chọn có giá cao và có lợi cho người bán. Trong một chu trình đầu cơ, giá cọc còn có thể tiếp tục bị đẩy cao hơn nữa. Khả năng chiếm dụng không có căn cứ giao dịch công bằng vì thế mà tăng lên đáng kể.

Một cách thức khác, khi người bán ẩn giá trị cọc vào trong các khoản thanh toán của bất động sản bán trên giấy phép, ngay cả với trường hợp đã thực hiện đúng yêu cầu chính sách. Giá trị quyền chọn thực này được tính như một phần của thanh toán hợp đồng. Chỉ có điều, khi tranh chấp, người ta có thể lấy lại. Trường hợp khách hàng của The Manor (Thành phố Hồ Chí Minh) đòi bồi thường do nhận nhà chậm là một điển hình. Lúc này, chúng ta tính hai chi phí: Chi phí cơ hội để mua một bất động sản khác tương đương đã tăng giá, và chi phí vốn bỏ ra, thấp nhất là bằng lãi suất ngân hàng cùng thời gian đáo hạn hoặc cơ hội kinh doanh thuận tiện nhất của người đi mua bất động sản.

\section{c - Yêu cầu quản lý thị trưòng bất động} sản và các phương pháp tham khảo

Tiền vay khế ước bất động sản ngày càng quan trọng đối với phần đông các gia đình ở một quốc gia công nghiệp phát triển như 
Hoa Kỳ. Bảng số liệu dưới đây minh họa rõ mức quan trọng tăng lên nhanh chóng này khoảng nửa thế kỷ vừa qua:

Bảng 2: Động thái về tiền vay khế ước bất động sản Hoa Kỳ qua một số năm

\begin{tabular}{|l|l|l|l|}
\hline & 1949 & 1979 & 2001 \\
\hline $\begin{array}{l}\text { Nợ mua BĐS/ } \\
\text { Tổng thu nhập } \\
\text { hộ gia đình }\end{array}$ & $20 \%$ & $46 \%$ & $73 \%$ \\
\hline $\begin{array}{l}\text { Nợ mua BĐS/ } \\
\text { Tổng tài sản } \\
\text { hộ gia đình }\end{array}$ & $15 \%$ & $28 \%$ & $41 \%$ \\
\hline
\end{tabular}

Nguồn: Green \& Watcher (2005)

Bản chất các công cụ tài chính nhằm hỗ trợ thanh toán bất động sản cũng thay đổi theo chiều hướng đa dạng và phức tạp hơn rất nhiều. Đó không phải vì người ta muốn tạo ra phức tạp (trên thực tế, cả thực hành lẫn quản lý đều muốn các mô hình đơn giản nhất), mà là do các tính chất phát sinh.

Trước năm 1930, tín dụng bất động sản Hoa Kỳ có các tính chất lãi suất linh hoạt, tỷ lệ thanh toán lần đầu rất cao, và khoản tín dụng có thời hạn ngắn. Điều này khá tương tự tình trạng Việt Nam hiện nay, với công cụ vay mua bất động sản của Techcombank, Sacombank...

Thời kỳ dài phát triển các thị trường tài chính, vượt qua các khủng hoảng đã khiến cho các dòng sản phẩm tài chính cho bất động sản cũng linh hoạt, đa dạng hơn, cung cấp thêm lựa chọn tín dụng (theo các chi tiết kỹ thuật khác nhau) cho người vay: Lãi suất cố định hay linh hoạt; Lựa chọn các kỳ hạn đáo hạn của khoản tài chính; Phần trả ban đầu nhỏ không gây ra gánh nặng tài chính trước mắt.

Sự can thiệp của các cơ quan lập pháp và chính phủ Hoa Kỳ đã có tác dụng đáng kể làm phát triển thị trường bất động sản và sự liên thông mạnh mẽ giữa các thị trường bất động sản - vốn - tiền tệ ở Hoa Kỳ kể từ nửa cuối thế kỷ XX.
Cuộc khủng hoảng 1929 - 1933 dẫn tới giai đoạn giá trị bất động sản sụt giảm mạnh, chỉ còn khoảng $50 \%$ của thời kỳ đỉnh cao trước khủng hoảng. Người mua nhà thấy tình trạng bất trắc đã chấp nhận tuyên bố mất khả năng thanh toán với các ngân hàng, chấm dút nghĩa vụ tài chính cá nhân. Làn sóng phát mại tài sản điển hình lên tới 250.000 vụ mỗi năm trong giai đoạn 1931 - 1935. Vào lúc xấu nhất, $10 \%$ số bất động sản bị siết nợ. Các tổ chức tín dụng phải bán tống các tài sản này để thu tiền về, và gây ra một áp lực sụt giá lớn trên thị trường nhà ở. Các tổ chức đặc biệt quan trọng được thành lập gồm:

HOLC: Huy động vốn từ trái phiếu được chính phủ bảo lãnh. Dùng vốn mua các bất động sản vỡ nợ. Phục hồi trạng thái. Đổi kỳ hạn khoản nợ. Đổi từ lãi suất biến động, ngắn hạn và không khấu trừ dần sang loại tài chính lãi suất cố định, dài hạn (20 năm trở lên) và khấu trừ dần tới khi hoàn thành nghĩa vụ tài chính. HOLC trong vụ này đã mua lại và xử lý khoảng 1 triệu hợp đồng vay.

FHA: Được thành lập để bảo hiểm cho các hợp đồng vay tài trợ bất động sản. Các hợp đồng bảo hiểm rất cần để bảo đảm cho những khế ước của HOLC có thể được giao dịch. HOLC không phải cơ quan kinh doanh bất động sản, nên cần tính thanh khoản để thu hồi tài chính. HOLC và FHA hợp súc thành một cơ cấu kỹ thuật tài chính cho phép các tổ chức tài chính không còn thanh khoản trở nên thanh khoản. Mặc dù không phải thần dược nhưng quả nhiên tác dụng rất tích cực, nó giúp phục hồi thị trường tài chính. Tới năm 1936, HOLC hoàn thành sứ mệnh và dừng hoạt động.

Tiếp tục sứ mệnh là FNMA ra đời năm 1938. Nó "hà hơi tiếp sức" cho FHA qua thị trường thứ cấp giao dịch các khế ước $\mathrm{FHA}$. FNMA phát hành trái phiếu mua các hợp đồng tín dụng ở mệnh giá. Những thay đổi này dẫn tới năm 1948, kỳ hạn vay dài nhất tăng lên 
30 năm (so với 20 năm trước đó). Năm 1956, FHA tăng tỷ lệ vay trên giá trị bất động sản lên tối đa $95 \%$ (so với trước đó $80 \%$ ) với xây dựng mới và $90 \%$ với nhà đang có.

Từ giai đoạn đó, Hoa Kỳ được ví là chuyển từ "quốc gia của những người thuê nhà trong phố sang những người sở hữu nhà ở các vùng ven, lân cận." Như vậy, bài học của Hoa Kỳ là việc triệt để thiết kế các công cụ và định chế quản lý sử dụng các phương tiện thị trường để điều tiết. Không phải trường hợp nào cũng có thể dự báo hết, như trường hợp của năm 1966, lãi suất trái phiếu tăng cao làm lượng tiền chảy mạnh từ $S \& L$ sang trái phiếu, khiến cơ cấu định chế phải thay đổi để xử lý khó khăn tài chính.

Một chuỗi các thay đổi làm cho thị trường hoạt động tốt hơn, việc quản lý hiệu quả hơn. Bản chất của quản lý tốt hơn cho vận hành thị trường là tổng hợp của 3 tính chất: Đa dạng lựa chọn tài chính cho người sử dụng; quản trị rủi ro tốt hơn; và, tính thanh khoản cao.

Tới năm 1980 thì chứng khoán hóa đã trở thành nguồn tài chính chủ yếu tài trợ cho hoạt động vay bất động sản nhà ở. Sự liên thông này khá toàn diện. Nó giúp đẩy toàn bộ thị trường bất động sản Hoa Kỳ lên mức giá trị 8.370 tỉ USD năm 2003.

Hiện ở Việt Nam cũng xuất hiện sự liên thông, nhumg mới ở trạng thái một chiều, túc là tạo nguồn cho việc hình thành bất động sản. Nói cách khác, quá trình chứmg khoán hóa để tái tạo lại tính thanh khoản cho hệ thống tài chính chưa có. Quá trình phân bổ rủi ro rất hẹp, trong phạm vi giữa số ít đối tượng tham gia giao dịch. Vì thế, thanh khoản ở Việt Nam chỉ bảo đảm được, khi giá bất động sản tăng. Ngược lại khi giảm thì hoàn toàn không có tính thanh khoản cao, do đó cũng không có múc cân bằng giá mới. Nên hiện tượng dễ thấy là giá thì vẫn đứng ở mức cao, nhưng không có giao dịch. Sau các chu kỳ trầm lắng, mức cao "kẹt giao dịch" đó tiếp tục là mặt bằng để đẩy tiếp giá thị trường sang điểm mất cân bằng trong một cơn sốt mới. Đó là lý do mà bất động sản Việt Nam có khi còn cao hơn những đô thị rất đắt đỏ của thế giới. Đây là "bong bóng" tự tồn tại do không "xì" được.

Hệ thống chính sách và định chế tốt sẽ cần xử lý hai việc kỹ thuật quan trọng: Cung cấp công cụ tài chính có lãi suất cố định cho người sử dụng mua bất động sản để phòng rủi ro lãi suất tăng; cung cấp cơ hội/khả năng cho người vay tái cấp tài chính để mua tài sản khi lãi suất giảm.

\section{d - Định hướng nghiên cứ chính sách}

Một số định hướng nghiên cứu có xem xét tới tính hũu dụng và tính khả thi được đề xuất là:

- Thiết kế và phát triển cơ sở dữ liệu thống kê cho thị trường bất động sản phục vụ nhu cầu của công tác quản lý, điều tiết thị trường và nghiên cún, đánh giá, dự báo tác oộng chính sách liên quan tới bất động sản.

- Bất động sản cần đi kèm hệ thống sản phẩm và định chế quản lý tín dụng liên quan bất động sản, các dạng tổ chức như Finnie Mae, Freddie Mac...

- Việc tính điểm tín dụng chắc chắn phải cải thiện với hệ thống ngân hàng thương mại, làm cơ sở để xây dựng và giới thiệu với công chúng tiêu dùng nhiều loại sản phẩm tài chính linh hoạt và đa dạng.

Chứng khoán hóa các tài sản có nguồn gốc bất động sản là một xu hướng và sử dụng nó là không thể tránh khỏi bởi nó tạo ra thanh khoản. Tính chất liên thông giữa các thị trường bất động sản - vốn - tiền tệ có thể hình thành một cơ chế lây lan và khuếch tán nhanh chóng các hiệu úmg biến động. Do vậy, cần sớm nghiên cứu các kỹ thuật xử lý rủi ro và tìm hiểu các công cụ tài chính phù hợp với điều kiện và mức độ phát triển của Việt Nam. 